\title{
The Moderating Effects of Callous-Unemotional Traits in the Relationship Between Adolescents' ADHD Symptoms and Cyberbullying Perpetration
}

\author{
Na Young $\operatorname{Sim}^{1}$, So Yean Lee ${ }^{2}$ \\ M.A., Department of Child Welfare and Studies, Sookmyung Women's University, Seoul, Korea ${ }^{1}$ \\ 중학생의 ADHD 증상과 사이버불링 가해행동의 관계에서 \\ 냉담-무정서 특질의 조절효과 \\ 심나영 ${ }^{1}$, 이소연 ${ }^{2}$ \\ 숙명여자대학교 아동복지학과 석사 ${ }^{1}$, 숙명여자대학교 아동복지학과 부교수 ${ }^{2}$
} Associate Professor, Department of Child Welfare and Studies, Sookmyung Women's University, Seoul, Korea ${ }^{2}$

Objectives: This study aimed to examine the moderating effects of callous-unemotional traits in the relationship between adolescents' ADHD subtypes and cyberbullying perpetration.

Methods: The participants included 457 students (184 boys; 273 girls) in the 1st 3 rd grade in middle school living in Gyeonggi-do. They completed questionnaires on ADHD Diagnostic Scale, Inventory of Callous-Unemotional Traits Scale, Cyberbullying Perpetration Scale. The study applied correlation analyses, and hierarchical regression analyses using SPSS 23.0. In addition, graphical analyses and simple slope analyses were conducted.

Results: The results indicated that adolescents' hyperactivity/impulsivity level positively increased cyberbullying perpetration level. In addition, callous-unemotional traits showed a significant moderating effect in the relationship between adolescents' inattention and cyberbullying perpetration.

Conclusions: Adolescents with high inattention and high callous-unemotional traits exhibited more severe aggressive behavior in the cyberspace. The results indicated that callous-unemotional traits are a risk factor in the relationship between inattention and cyberbullying perpetration.

Keywords: ADHD symptoms, attention deficit, hyperactivity, cyberbullying perpetration, callousunemotional traits

\section{Introduction}

최근 정보통신기술의 발전으로 청소년에게 인터넷과 스마트 기기는 생활필수품이 되었다. 한국 인터넷 진흥원이 5,400명 의 청소년을 대상으로 조사한 '2016년 인터넷 이용 실태조사' 에 따르면 청소년의 인터넷 이용률은 $100 \%$ 를 나타내고 있으

Corresponding Author: So Yean Lee, Associate Professor, Department of Child Welfare and Studies, Sookmyung Women's University, 100, Cheongpa-ro 47, Yongsan-gu, Seoul, Korea

E-mail: leesy@sm.ac.kr
며 스마트폰, 스마트패드, 웨어러블 기기 등을 통한 인터넷 이 용률은 96\%로 보고되었다(Korea Internet \& Security Agency, 2017). 스마트 기기의 대중화로 청소년들은 시간과 장소에 구 애받지 않고 사이버 공간에서 타인과 상호작용하고 자신을 자 유롭게 표현하며 인간관계의 확장 및 강화를 경험한다(Park, 2016). 반면 청소년들의 생활이 사이버 공간으로 확장되면서

(C)The Korean Association of Child Studies

This is an Open Access article distributed under the terms of the Creative Commons Attribution Non-Commercial License (http:// creativecommons.org/licenses/by-nc/4.0) which permits unrestricted noncommercial use, distribution, and reproduction in any medium, provided the original work is properly cited. 
사이버 상에서 친구간의 욕설, 놀림, 소문 퍼트리기 등 문제 행 동을 보이는 부정적 현상이 증대되고 있다(Ahn \& Lee, 2014; J. H. Lee, 2017). 특히 스마트 기기의 보편화에 따라 사이버 공간 에서 일어나는 사이버 폭력 현상이 사회적 문제로 대두되고 있 다. 이와 같이 사이버 공간에서 일어나는 사이버 폭력 행동을 '사이버불링(cyberbullying)'이라고 하는데, 사이버불링은 컴퓨 터, 휴대 전화 및 기타 전자 기기를 통한 고의적이고 반복적인 위협을 뜻한다(Patchin \& Hinduja, 2015). 즉 사이버불링은 집 단이나 개인의 형태로 스스로를 보호할 수 없는 피해자를 대상 으로 한 의도적인 공격행동이며(Smith et al., 2008), 전자기기를 통한 욕설과 협박, 괴롭힘, 원치 않은 폭언, 거짓정보 유포 그리 고 사회관계를 방해하거나 고립시키기 등과 같은 위협적 행동 을 가하는 것을 의미한다(E. K. Kim, 2012). 사이버불링 가해행 동은 과거 오프라인 폭력과 달리 시·공간을 초월하여 언제, 어 디서든 일어날 수 있기 때문에 피해자들은 더 큰 고통을 호소 한다(Sticca \& Perren, 2013). 실제 사이버불링의 피해 중학생들 은 언제, 어디서, 어떻게 괴롭힘을 당할지 모른다는 불안감으 로 오프라인 폭력보다 정신적 상처가 더 오래감을 호소했다(C. Lee, 2016). 이처럼 심각한 피해를 야기할 수 있는 사이버불링 가해행동을 유발하는 요인에 대한 연구가 진행되고 있다.

National Information Society Agency (2016) 국내 중·고등학 생 2,000명을 대상으로 한 사이버불링 실태조사에 따르면 사 이버불링 가해행동의 비율이 $20 \%$ 를 선회할 뿐만 아니라, 중 학생의 사이버불링 가해행동이 2014년 16.9\%에서 2015년에 $20 \%$ 로 증가한 것으로 보고되었다. 특히 중학생은 초등학생과 고등학생 보다 상대적으로 사이버불링 가해행동을 더 많이 보 이는 것으로 보고되었다(Ministry of Education, 2018). 이 시기 의 중학생은 아동기에서 성인기로 넘어가는 과도기적 단계로 써 신체의 급격한 변화를 느끼고 자아정체성을 확립하는 시기 로 감정적으로 예민하고 감정 기복이 심하여 분노 감정을 쉽 게 느끼고 충동적인 행동을 보이는 등 정서적으로 불안정한 상태를 경험한다(Y. Kim \& Kang, 2016). 이러한 정서적 혼란은 청소년 초기에 가장 극심하게 나타나며 청소년 후기로 갈수록 약하게 나타난다(S. Lee, 2017). 청소년 초기에 불안한 정서를 극복하지 못하면 사이버 공간에서 충동적으로 공격성을 표현 할 수 있다(Paek, 2015). 이러한 점들을 모두 종합해보았을 때, 청소년, 특히 중학생의 경우 사이버불링 가해행동을 보일 가 능성이 가장 높음을 추측해 볼 수 있다.

선행연구를 통해 확인된 사이버불링 가해행동에 영향을 미 치는 변인들은 사이버불링 피해경험, 채팅 또는 SNS 사용시 간, 인지적 공감 결여, 부모애착, 학교생활 만족(C. Lee \& Shin,
2017), Attention Deficit Hyperactivity Disorder (ADHD; Yen et al., 2014), 부모통제(Ho, Chen, \& Ng, 2017), 규범의식 결여 (Yoo \& Kim, 2011) 등이다. 최근 사이버불링 가해행동의 유 발요인인 개인, 폭력경험, 가정, 학교, 또래, 사이버환경 변인 을 범주화하여 실시한 메타분석 결과에 따르면, 공감, 자아존 중감, 우울, 감각추구성향, 자기통제력, 공격성, 정서조절, 충 동성 등을 나타내는 개인변인이 사이버불링 가해행동의 유 발요인 중 효과크기가 가장 큰 것으로 나타났다(S. Kim, Bang, $\& \mathrm{Han}, 2017)$. 가해요인 중 특히 $\mathrm{ADHD}$ 증상이 중요한 요인 으로 연구되고 있다. $\mathrm{ADHD}$ 증상을 지닌 중학생은 낮은 공 감능력 및 자기통제력, 높은 충동성의 개인적인 특징이 두드 러지게 나타난다. 이러한 $\mathrm{ADHD}$ 증상을 지닌 중학생은 사이 버 공간에서 타인에게 위협을 가하는 행동을 나타낼 수 있다 (Heiman, Olenik-Shemesh, \& Eden, 2015; Yen et al., 2014).

주의력 결핍 과잉행동 장애(ADHD) 증상은 산만하고 부 주의한 주의력 결핍과 자신의 행동을 적절히 통제하지 못 하는 과잉행동·충동성으로 나타난다(American Psychiatric Association, 2013). 이러한 중학생의 $\mathrm{ADHD}$ 증상에 따른 사이 버불링 가해행동의 관계를 검토해보면, 주의력 결핍을 지닌 청소년은 부주의함으로 인하여 상황과 문맥 정보를 활용하여 타인의 정서를 이해하는 데 어려움을 느끼기 때문에 각 상황 에 처해있는 타인의 정서를 올바르게 인지하지 못할 수 있다 (Da Fonseca, Seguier, Santos, Poinso, \& Deruelle, 2009). 이는 사 이버 공간에서 자신이 작성한 글이 타인에게 상처가 될 수 있 다는 것을 인식하지 못함으로써 타인에게 위협적인 행동을 할 수 있다(Chung \& Du, 2015). 게다가 주의력 결핍을 지닌 청소 년은 학업성취와 친구들과의 사회적 관계에서 불만족을 느끼 는데, 이러한 부정적 정서로부터 벗어나기 위해 온라인을 사 용하게 된다. 이는 온라인 활동 시간을 증가시키게 되어 사이 버불링 가해행동을 높이게 될 수 있다(Ceranoglu, 2018). 또한 과잉행동·충동성을 보이는 청소년은 자신의 슬픔과 분노 감 정을 더욱 강하게 느끼지만, 낮은 자기통제력으로 인하여 충 동적으로 타인에게 부정적 정서를 표출할 수 있다(Braaten $\&$ Rosén, 2000; Unnever \& Cornell, 2003; Wehmeier, Schacht, \& Barkley, 2010). 즉 과잉행동.충동성을 보이는 청소년은 사이버 공간에서 부정적 정서를 경험한 경우 충동적으로 다른 사람에 게 사이버불링 가해행동을 보일 수 있다(Mitchell \& Hussain, 2018; Sourander et al., 2010; Yen et al., 2014). 이처럼 ADHD 하위증상인 주의력 결핍과 과잉행동·충동성은 뚜렷하게 다 른 행동 특징을 나타내고 있기 때문에 두 증상을 구분하여 (Milich, Balentine, \& Lynam, 2001) 사이버불링 가해행동에 미 
치는 영향을 검토하는 것이 필요하다.

한편, 청소년 $\mathrm{ADHD}$ 증상이 사이버불링 가해행동과 관련 성이 있는 것으로 나타났지만, $\mathrm{ADHD}$ 증상을 보이는 청소년 이 모두 사이버불링을 가하는 것은 아니다. 일례로 $\mathrm{ADHD}$ 를 진단받은 청소년 140 명 중 22명(16.7\%)만이 사이버불링 가해 행동 경험이 있다고 보고하였다(Heiman et al., 2015). 이와 같 이 청소년의 $\mathrm{ADHD}$ 증상이 사이버불링 가해행동에 일관되게 영향을 미치지 않는 것은 두 변인 간의 관계를 추가적으로 설 명하는 변인이 존재할 수 있음을 의미한다.

공격행동에 영향을 미치는 요인을 설명한 Blair (1995)의 ‘폭 력억제기제(violence inhibition mechanism)' 이론에 따르면, 청 소년은 타인의 정서에 공감하여 폭력억제기제를 활성화시킴 으로써 공격 행동을 철회시킨다. 하지만 높은 공격성을 보이 는 중학생의 경우 폭력억제기제의 비활성화로 타인이 보내는 고통 신호에 둔감하고 공감하지 못할 뿐만 아니라 자신의 행 동에 죄책감을 느끼지 못하여 지속적인 공격행동을 보이게 된 다. 이처럼 죄책감과 공감의 결여, 타인의 감정에 무감각함, 제 한된 정서표현 등을 포함한 개인의 정서적 특징을 냉담-무정 서 특질이라고 한다(Fanti, Colins, Andershed, \& Sikki, 2017).

냉담-무정서 특질은 사이버불링 가해행동에 영향을 미치 는 개인적 변인으로 보고되고 있다(Fanti, Demetriou, \& Hawa, 2012). 냉담-무정서 특질이 높은 청소년의 경우 타인의 고통 신호에 주의를 기울이는 것과 공감하는 것에 어려움이 있다. 즉 냉담-무정서 특질이 높은 청소년은 사이버 공간에서 위협 을 당한 피해자의 두려움과 고통에 공감하지 못함으로써 지속 적인 공격행동을 보일 수 있다. 냉담-무정서 특질과 사이버불 링 가해행동의 관계에 대한 선행 연구를 검토하면, 낮은 냉담무정서 특질을 보이는 청소년의 경우 사이버불링 가해행동을 할 가능성이 낮게 나타나지만 높은 냉담-무정서 특질을 보이 는 청소년의 경우 사이버불링 가해행동을 할 가능성이 높게 나타났다(Kokkinos \& Voulgaridou, 2017).

한편, 냉담-무정서 특질은 중학생의 $\mathrm{ADHD}$ 증상과 사이 버불링 가해행동의 관계에서 위험요인으로 작용할 가능성 이 제기되고 있다. $\mathrm{ADHD}$ 증상을 보이는 청소년 중 냉담-무 정서 특질의 유무에 따라 문제행동에 있어서 정도의 차이가 나타났다(Barry et al., 2000; Fanti et al., 2017). ADHD와 적대 적 반항장애(Oppositional Defiant Disorder [ODD]) 또는 품행 장애(Conduct Disorder [CD])를 모두 보이는 청소년은 충동성 과 과잉행동 그리고 반사회적 행동을 나타내지만, 냉담-무정 서 특질까지 가진 청소년은 냉담함, 행동 억제 결핍, 죄책감 결핍, 낮은 공감능력, 낮은 불안감의 특징을 동시에 보임으로
써 더욱 심각한 문제행동이 나타났다. 특히 $\mathrm{ADHD}$ 와 $\mathrm{ODD} /$ $\mathrm{CD}$ 증상을 모두 보이는 아동-청소년 중 높은 냉담-무정서 특 질을 지닌 경우 낮은 냉담-무정서 특질을 보이는 $\mathrm{ADHD}$ 와 $\mathrm{ODD} / \mathrm{CD}$ 의 아동.청소년보다 스릴과 모험을 추구하는 성향 이 높고 행동 억제 결핍을 보여 더욱 심각한 외현화 문제행동 을 보일 것으로 제시되었다(Barry et al., 2000). 게다가 냉담-무 정서 특질의 수준은 높아지거나 유지될 수 있는데, 이러한 냉 담-무정서 특질의 발달 궤적에 영향을 미치는 개인의 특성으 로 $\mathrm{ADHD}$ 가 보고되고 있다(Fanti et al., 2017). 즉 높은 충동성 과 낮은 자기조절능력, 실행기능의 결함을 보이는 $\mathrm{ADHD}$ 증 상은 냉담-무정서 특질을 증가시킬 뿐만 아니라 높은 냉담-무 정서 특질을 안정적으로 유지시키는 데 기여한다. 냉담-무정 서 특질이 증가하거나 높은 상태에서 유지될 때, 더욱 위험하 고 심각한 반사회적 행동이 나타날 수 있다(Fontaine, Colins, Andershed, Sikki, \& Viding, 2011). 이러한 오프라인에서의 가 해행동은 사이버 공간에서의 가해행동의 위험요인과 공격적 양상이 유사하게 나타나며, 동일한 이론적, 경험적 지식의 맥 락에서 고려되어진다(Mehari, Farrell, \& Le, 2014). 이처럼 청소 년의 $\mathrm{ADHD}$ 증상과 냉담-무정서 특질이 상호작용하여 사이 버불링 가해행동에 영향이 미침을 추측할 수 있다. $\mathrm{ADHD}$ 증 상과 냉담-무정서 특질이 함께 나타나는 경우 사이버불링 가 해행동이 더욱 심각한 형태로 나타날 수 있으며, 특히 높은 냉 담-무정서 특질을 보일 때 사이버 공간에서 더욱 충동적으로 위협을 가할 것으로 추측된다.

이처럼 중학생의 $\mathrm{ADHD}$ 증상과 냉담-무정서 특질은 독립 적이지만 상호 관련성이 있으며 공격적인 행동에 영향을 미 친다는 결과들이 있다. 때문에 $\mathrm{ADHD}$ 증상을 보이는 중학생 중 개인 내적 특징인 냉담-무정서 특질의 유무에 따라 치료방 법을 달리 해야 된다고 제시되기도 한다(Waschbusch, Carrey, Willoughby, King, \& Andrade, 2007). 이에 ADHD 증상과 냉 담-무정서 특질로 인해 사이버불링 가해행동을 지속적으로 하는 중학생에게 효과적인 치료적 개입을 위해, 우선 세 변 인 간의 관계를 이해하는 것이 필요하다. 그러나 중학생의 $\mathrm{ADHD}$ 증상의 총점을 통해 관련 변인과의 관계를 탐색하는 것은 $\mathrm{ADHD}$ 하위증상 각각과 냉담-무정서 특질이 상호작용 하여 사이버불링 가해행동에 영향을 미치는지에 대해 구체적 으로 파악하기 어렵다. 이에 중학생의 $\mathrm{ADHD}$ 하위증상별로 관련 변인과의 관계를 탐색한다면, 향후 냉담-무정서 특질과 주의력 결핍 또는 과잉행동·충동성을 동시에 보이는 중학생 에게 사이버불링 가해행동에 대한 치료적 개입 시 구체적이고 차별적인 치료 계획을 세울 수 있을 것이다. 따라서 본 연구는 
$\mathrm{ADHD}$ 하위증상과 냉담-무정서 특질로 인해 사이버불링 가 해행동을 일으키는 중학생에게 효과적인 치료 개입을 위한 변 인들의 관계를 이해하는 데 도움이 될 것이다.

따라서 본 연구에서는 중학생을 대상으로 $\mathrm{ADHD}$ 하위증 상인 주의력 결핍과 과잉행동.충동성 증상과 냉담-무정서 특 질이 사이버불링 가해행동에 어떠한 영향을 미치는지 분석하 고, 중학생의 $\mathrm{ADHD}$ 하위증상이 사이버불링 가해행동에 미 치는 영향에 대한 냉담-무정서 특질의 조절효과를 검증하고 자 한다. 본 연구는 중학생의 사이버불링 가해행동에 대한 이 해와 더불어 사이버불링 가해행동을 감소시키거나 예방하기 위한 중재 방안을 마련하는 데 기여할 것으로 사료된다. 본 연 구의 연구문제는 다음과 같다.

\section{연구문제 1}

중학생의 ADHD 하위증상과 냉담-무정서 특질이 사이버불링 가해행동에 영향을 미치는가?

\section{연구문제 2}

중학생의 ADHD 하위증상과 사이버불링 가해행동의 관계에 서 냉담-무정서 특질의 조절효과는 어떠한가?

\section{Methods}

\section{연구대상}

본 연구의 대상은 수도권 중학교에 재학 중인 $1,2,3$ 학년 학생 457명이었다. 본 연구대상자의 성별 구성은 전체 457 명의 학 생 중 남자 184명(40.3\%), 여자 273명(59.7\%)이었으며, 학년 구성은 1학년 145명(31.7\%), 2학년 153명(33.5\%), 3학년 159 명 $34.8 \%)$ 이었다. 연구대상의 성별 비율에서 다소 차이가 발 생하여, 성별에 따른 $\mathrm{ADHD}$ 증상, 냉담-무정서 특질, 사이버 불링 가해행동의 차이가 존재하는지 확인하기 위해 독립표본 $t$ 검증을 실시하였다. 그 결과 남학생은 여학생보다 냉담-무 정서 특질과 $(t=3.30, p<.01)$ 사이버불링 가해행동 $(t=1.99, p$ $<.05)$ 에서 유의미하게 높게 나타났다. 이에 연구 대상의 집단 간 차이가 연구 결과를 타당하게 해석하는데 영향을 미칠 수 있어 성별을 더미변수화하여 통제변인으로 설정하였다. 이에 모든 위계적 회귀분석에서는 성별을 통제변인으로 하여 1 단 계에 투입하고 통제변인인 성별의 영향력을 배제한 상태에서 각 연구 문제를 분석하였다.

\section{연구도구}

\section{$\mathrm{ADHD}$ 진단 척도}

중학생의 $\mathrm{ADHD}$ 증상을 측정하기 위하여 We \& Chae (2004) 가 DSM-IV에 규정되어 있는 $\mathrm{ADHD}$ 진단 기준을 바탕으로 재구성한 질문지를 사용하였다. 이 척도는 주의력 결핍(9문 항)과 충동성 및 과잉행동(9문항)에 관한 총 18 개의 문항으 로 구성되었다. 문항에 대한 예로 "나는 공부, 일 또는 다른 활 동에 있어서 부주의하게 실수를 많이 한다.", "나는 제자리에 가만히 있지 못하고 손발을 자주 움직인다." 등이 있다. 이 척 도는 각 문항에 대해 전혀 그렇지 않다(1점)부터 항상 그렇다 (4점)까지 Likert 4점 척도로 평정하는 자기 보고형 질문지이 다. 본 척도는 점수가 높을수록 $\mathrm{ADHD}$ 증상이 높은 것을 의 미한다. 본 연구에서 사용된 $\mathrm{ADHD}$ 진단 척도의 내적합치도 (Cronbach's $\alpha$ )는 .86이었으며, 각 하위증상별 신뢰도는 주의 력결핍. .77 , 과잉행동·충동성이 .83이었다. 본 연구에서는 각 하위증상별 총점을 사용하였다.

$$
\text { 냉담-무정서 특질 척도 }
$$

중학생의 냉담-무정서 특질을 측정하기 위해 Kwon, Son, \& Hwang (2010)이 중학생을 대상으로 번안 및 타당화한 냉담-무 정서 특질 척도(Inventory of Callous-Unemotional Traits [ICU], Kwon et al., 2010)를 사용하였다. 이 척도는 24 개 문항으로 전 혀 그렇지 않다(0점)부터 매우 그렇다(3점)까지 Likert 4점 척 도로 평정하는 자기 보고형 질문지이다. 문항에 대한 예로 "나 는 내 감정을 다른 사람에게 보여주지 않는다.", "나는 어떤 일 을 잘못했을 때 양심의 가책을 느끼거나 후회하지 않는다." 등 이 있다. 본 척도는 점수가 높을수록 냉담-무정서 특질이 높은 것을 의미한다. 본 연구에서 사용된 냉담-무정서 특질 척도의 내적합치도(Cronbach's $\alpha$ )는 .69이었다. 본 연구에서는 총점을 사용하였다.

\section{사이버불링 가해행동 척도}

중학생의 사이버불링 가해행동을 측정하기 위해 E. K. Kim (2012)이 개발하고 타당화한 사이버불링 가해행동 척도를 사 용하였다. 본 척도는 총 13 문항으로 전혀 그렇지 않다(1점)부 터 매우 그렇다(5점)까지 Likert 5점 척도로 평정하는 자기 보 고형 질문지이다. 문항에 대한 예로 "인터넷을 통해 알게 된 
사람에게 욕설을 한 적이 있는가?”, “휴대전화 문자메시지(카 카오톡, 라인 등)를 이용하여 누군가에게 욕을 하거나 괴롭힌 적이 있는가?” 등이 있다. 본 척도는 점수가 높을수록 사이버 불링 가해행동 경험이 많다는 것을 의미한다. 본 연구에서 사 용된 사이버불링 가해행동 척도의 내적합치도(Cronbach's $\alpha$ ) 는 .84 이다. 본 연구에서는 총점을 사용하였다.

\section{연구절차}

본 연구는 2017년 12월부터 2018년 2월까지 연구자가 경기 지 역에 소재한 중학교 4곳에 직접 방문하여 학교장과 교사에게 연구의 취지 및 내용, 절차를 설명하고 협조를 구한 후 설문조 사를 실시하였다. 본 연구는 중학교에 재학 중인 $1,2,3$ 학년 500 명을 대상으로 실시하였고, 배포된 설문지 500부 중 469부 를 회수하였다. 회수된 설문지 중 연구참여에 대한 연구대상 자와 보호자의 동의 서명이 되어있지 않은 5부, 응답이 $90 \%$ 이상 누락되는 등 불성실하게 응답한 7부를 제외하여 총 457 부를 분석에 사용하였다. 자료수집과 연구절차는 숙명여자 대학교 생명윤리심의위원회의 승인을 받았다(IRB 승인번호 SMWU-1711-HR-124).

\section{자료분석}

본 연구에서는 자료 분석을 위해 SPSS 23.0 (IBM Co., Armonk, $\mathrm{NY}$ ) 프로그램을 사용하여 빈도분석, 신뢰도 검증, Pearson 상 관분석과 조절효과 검증을 위해 위계적 회귀분석을 실시하였 다. 조절효과 검증 시 다중공선성을 줄이고 결과를 보다 의미 있게 해석하기 위해 독립변인과 조절변인의 평균중심화(mean centering)를 실시하였다. 중학생의 $\mathrm{ADHD}$ 증상과 냉담-무정 서 특질의 평균값을 중심으로 표준편차 \pm 1 의 값을 각 변인의
상, 하 수준으로 구분하고 회귀식을 이용하여 이를 그래프로 제시하였다. 그리고 상호작용효과가 어떠한 조건에서 나타나 는지를 구체적으로 설명하기 위해 단순 기울기 분석을 실시하 여 각 조건하의 조절효과의 유의성을 하였다.

\section{Results}

\section{주요 변인의 기술통계 및 성별에 따른 평균 차이 검증}

주요 변인의 일반적인 경향을 알아보기 위해 기술통계 분석을 실시하였으며, 중학생의 성별에 따른 변인들의 평균 차이를 검 증하기 위해 독립표본 $t$ 검정을 실시하였다. Table 1 에 제시된 바와 같이, 냉담-무정서 특질과 사이버불링 가해행동은 성별 에 따라 유의미한 차이가 나타났는데, 남학생이 여학생보다 냉 담-무정서 특질과 사이버불링 가해행동이 더 높게 나타났다.

\section{중학생의 $\mathrm{ADHD}$ 증상과 냉담-무정서 특질이 사이버불링 가해행동에 미치는 영향}

중학생의 $\mathrm{ADHD}$ 증상과 냉담-무정서 특질이 사이버불링 가 해행동에 미치는 영향을 검증하기 위해 우선, 주요 변인 간의 상관관계를 확인하고자 Pearson 상관분석을 실시하였다. 그 결 과 Table 2 와 같다.

중학생의 $\mathrm{ADHD}$ 하위증상과 냉담-무정서 특질이 사이버 불링 가해행동에 미치는 영향을 확인하기 위해 위계적 회귀 분석을 실시하였으며, 그 결과는 Table 3 과 같다. 1 단계에서는 통제변인인 성별을 투입하고, 2단계에서는 $\mathrm{ADHD}$ 하위증상 과 냉담-무정서 특질을 추가로 투입하여 사이버불링 가해행

Table 1

Descriptive Statistics and Gender Differences for ADHD Symptoms, Callous-Unemotional Traits, Cyberbullying Perpetrations

\begin{tabular}{|c|c|c|c|}
\hline & $\begin{array}{c}\text { Male } \\
(n=184)\end{array}$ & $\begin{array}{c}\text { Female } \\
(n=273)\end{array}$ & \\
\hline Variables & $M(S D)$ & $M(S D)$ & $t$ \\
\hline \multicolumn{4}{|l|}{ ADHD symptoms } \\
\hline Inattention & $16.33(3.76)$ & $16.31(4.04)$ & .04 \\
\hline Hyperactivity/impulsivity & $14.16(4.10)$ & $13.81(4.29)$ & .88 \\
\hline Callous-unemotional traits & $24.13(6.34)$ & $22.02(6.88)$ & $3.30^{* *}$ \\
\hline Cyberbullying perpetration & $16.97(5.25)$ & $16.03(4.73)$ & $1.99^{*}$ \\
\hline
\end{tabular}

${ }^{*} p<.05 .{ }^{* *} p<.01$. 
Table 2

Correlations of ADHD Symptoms, Callous-Unemotional Traits, Cyberbullying Perpetration

\begin{tabular}{|c|c|c|c|c|}
\hline Variables & 1 & 2 & 3 & 4 \\
\hline 1. Inattention ${ }^{\mathrm{a}}$ & - & & & \\
\hline 2. Hyperactivity/impulsivity & $.54^{* *}$ & - & & \\
\hline 3. Callous-unemotional traits & $.33^{* *}$ & $.31^{* *}$ & - & \\
\hline 4. Cyberbullying perpetration & $.29^{* *}$ & $.39^{* *}$ & $.30^{* *}$ & - \\
\hline
\end{tabular}

Note. $N=457$.

${ }^{\mathrm{a} A D H D}$ symptoms.

${ }^{* *} p<.01$.

Table 3

Hierarchical Regression Analyses: Moderating Effects of Callous-Unemotional Traits on the Relationship Between ADHD Subtypes and Cyberbullying Perpetration

\begin{tabular}{|c|c|c|c|}
\hline & Step1 & Step2 & Step3 \\
\hline Variables & $\beta$ & $\beta$ & $\beta$ \\
\hline Gender $^{\alpha}$ & $-.94^{*}$ & -.53 & -.55 \\
\hline \multicolumn{4}{|l|}{$\mathrm{ADHD}$} \\
\hline Inattention $(\mathrm{A})$ & & .08 & .05 \\
\hline Hyperactivity/impulsivity (B) & & $.35^{* * *}$ & $.32^{* * *}$ \\
\hline Callous-unemotional traits (C) & & $.14^{* * *}$ & .13 \\
\hline $\mathrm{A} \times \mathrm{C}$ & & & $.01^{*}$ \\
\hline $\mathrm{B} \times \mathrm{C}$ & & & .02 \\
\hline$R^{2}$ & $.01^{*}$ & $.20^{* * *}$ & $.22^{* *}$ \\
\hline$\Delta R^{2}$ & $.01^{*}$ & $.19^{* * *}$ & $.02^{* *}$ \\
\hline$F$ & $3.96^{*}$ & $27.36^{* * *}$ & $20.65^{* * *}$ \\
\hline
\end{tabular}

Note. $N=457$.

${ }^{\alpha} 0=$ male, 1 = female.

${ }^{*} p<.05 .{ }^{* *} p<.01 .{ }^{* * *} p<.001$.

동에 미치는 영향을 검증하였다. 1단계에 투입된 성별이 사이 버불링 가해행동에 유의한 영향을 미치는 것으로 나타났다 $(\beta$ $=-.94, p<.05)$. 이는 남학생일수록 사이버불링 가해행동을 더 많이 보임을 의미한다. 2단계에 추가로 투입된 주의력 결핍, 과잉행동 - 충동성과 냉담-무정서 특질 중 과잉행동 - 충동성 $(\beta$ $=.35, p<.001)$ 과 냉담-무정서 특질 $(\beta=.14, p<.001)$ 이 사이버 불링 가해행동에 유의한 영향을 미치는 것으로 나타났다. 이 는 과잉행동 - 충동성과 냉담-무정서 특질이 높은 학생일수록 사이버불링 가해행동을 더 많이 보임을 의미한다. $\mathrm{ADHD}$ 하 위증상과 냉담-무정서 특질을 추가한 2단계에서 설명력은 $1 \%$ 에서 $20 \%$ 로 증가하였다 $(F=27.36, p<.001)$.

\section{중학생의 $\mathrm{ADHD}$ 증상이 사이버불링 가해행 동에 미치는 영향에 대한 냉담-무정서 특질의 조절효과}

중학생의 $\mathrm{ADHD}$ 하위증상인 주의력 결핍, 과잉행동 - 충동성 과 사이버불링 가해행동의 관계에서 냉담-무정서 특질의 조 절효과를 검증하고자 위계적 회귀분석을 실시하였다. 1 단계 에서는 통제변인인 성별을 투입하였고, 2 단계에서는 중학생 의 $\mathrm{ADHD}$ 하위증상과 냉담-무정서 특질을 추가 투입하였다. 3 단계에서는 중학생의 $\mathrm{ADHD}$ 하위증상 각각과 냉담-무정서 특질의 상호작용변인을 추가로 투입하여 사이버불링 가해행 동에 유의한 영향을 미치는지 확인하였다. 분석 전, 다중공선 
성을 줄이고 결과를 의미있게 해석하기 위해 $\mathrm{ADHD}$ 하위증 상, 냉담-무정서 특질의 변인들을 평균중심화(mean centering) 하였다. 본 연구에서는 분산팽창요인이 모두 1.5 이하로 독립 변인들 간의 다중공선성 문제가 없었다. 이에 따른 분석 결과 는 앞서 제시한 Table 3에서 확인할 수 있다.

위계적 회귀분석 결과, 주의력 결핍, 과잉행동 · 충동성과 냉 담-무정서 특질의 상호작용항이 추가로 투입된 3단계에서 주 의력 결핍과 냉담-무정서 특질의 상호작용항이 사이버불링 가 해행동에 대해 $2 \%$ 추가 설명량을 나타냈다 $(\beta=.01, p<.05)$. 이 는 주의력 결핍 증상이 사이버불링 가해행동에 미치는 영향에 있어서 냉담-무정서 특질의 상호작용항이 조절효과가 있음을 의미한다.

한편 주의력 결핍과 사이버불링 가해행동의 관계에서 상호 작용 효과의 양상을 구체적으로 살펴보기 위해 회귀식을 통 해 냉담-무정서 특질의 평균값을 중심으로 표준편차 \pm 1 의 값 을 각 변인의 상, 하 수준으로 구분하여 단순 기울기 검증을 실 시하였다. 이를 비교한 결과는 Figure 1 과 같다. 높은 냉담-무 정서 특질은 통계적으로 유의하게 나타난 $(\beta=.39, t=5.67, p<$ .001) 반면, 낮은 냉담-무정서 특질은 통계적으로 유의하지 않 은 것으로 나타났다 $(\beta=.04, t=0.41, p>.05)$. 이는 높은 냉담무정서 특질을 보이고 주의력 결핍도 높은 경우 사이버불링 가해행동에 미치는 영향이 더 커지는 것을 의미하나 낮은 냉 담-무정서 특질의 경우 주의력 결핍이 사이버불링 가해행동 에 미치는 영향이 크지 않다는 것을 의미한다.

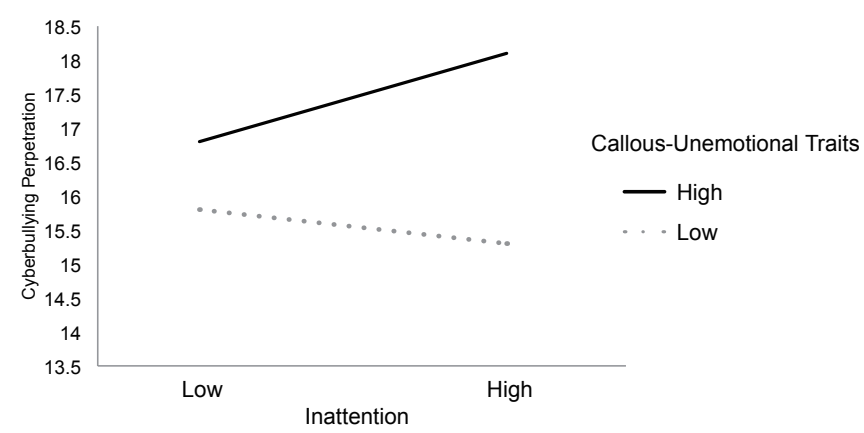

Figure 1. Moderating effects of callous-unemotional traits on the relation between inattention and cyberbullying perpetration.

\section{Discussion}

본 연구에서는 중학생의 $\mathrm{ADHD}$ 증상과 냉담-무정서 특질이 사이버불링 가해행동에 미치는 영향을 검증하고 $\mathrm{ADHD}$ 증상 과 사이버불링 가해행동의 관계에서 냉담-무정서 특질의 조
절효과를 규명하였다. 연구의 주요한 결과를 중심으로 논의하 고 시사하는 바를 서술하면 다음과 같다.

첫째, 중학생의 $\mathrm{ADHD}$ 하위증상 중 과잉행동 - 충동성은 사이버불링 가해행동에 유의한 정적 영향을 미쳤지만 주의 력 결핍은 사이버불링 가해행동에 유의한 영향을 미치지 않 는 것으로 나타났다. 이는 과잉행동 · 충동성 증상이 심한 중 학생일수록 사이버불링 가해행동을 할 가능성이 높음을 의미 하며, 청소년의 과잉행동 · 충동성이 사이버불링 가해행동에 선행한다는 연구 결과(Yen et al., 2014)를 지지하는 것이다. 또 한 과잉행동 · 충동성 증상을 보이는 중학생은 통제와 조절 능 력이 부족하여 스마트폰 이용 시 충동적으로 문제 행동을 보 일 수 있음을 보고한 선행연구 결과(Mitchell \& Hussain, 2018) 와도 맥을 같이한다. 이러한 원인을 구체적으로 살펴보면, 과 잉행동 · 충동성 증상을 보이는 중학생은 타인의 자극에 의해 슬픔이나 분노와 같은 부정적 감정을 더욱 강하게 느끼는데, 자신의 부정적 감정을 완화시키기 위하여 과도하고 충동적으 로 타인에게 공격을 가하게 된다(Factor, Rosen, \& Reyes, 2016; Shin \& Lee, 2009). 이러한 과잉행동 · 충동성을 지닌 중학생 의 특성은 사이버 공간에서 공격행동을 높일 수 있다(Pabian \& Vandebosch, 2016). 게다가 과잉행동 · 충동성 증상을 보이 는 중학생은 즐거움을 추구하려는 특성을 보이며, 점점 더 강 한 자극을 통해 재미를 느끼고자 하는데, 이러한 특성을 보이 는 중학생은 괴롭힘을 당하는 피해자의 정서 및 행동 반응을 즐거움으로 인식하여 더 큰 즐거움을 위해 괴롭힘을 반복하고 충동적으로 행동할 수 있다(Chou, Liu, Yang, Yen, \& Hu, 2018). 즉 과잉행동 · 충동성을 보이는 중학생은 더 재미있는 자극을 위하여 충동적으로 사이버 공간에서 타인에게 가해행동을 보 일 수 있음을 유추할 수 있다. 반면 중학생의 주의력 결핍 증상 은 사이버불링 가해행동에 유의한 영향을 미치지 않는 것으 로 나타났다. 이는 주의력 결핍 증상이 사이버불링 가해행동 에 직접적인 영향을 미치지 않는다는 것을 의미한다. 주의력 결핍 증상을 보이는 중학생은 자주 공상에 잠기고 인지 처리 속도가 느린 특성을 보이며 문제 상황에서 수동적이고 철회 하는 행동 특성을 보인다(Mikami, 2010). 이러한 특성으로 인 해 주의력 결핍 증상을 보이는 중학생은 사이버 공간에서 다 른 사람이 이야기한 내용을 기억하지 못하거나 반응을 하지 않을 수 있으며, 문제 상황에서 철회하는 모습을 보일 수 있다 (Mikami, Huang-Pollock, Pfiffner, McBurnett, \& Hangai, 2007).

둘째, 냉담-무정서 특질은 사이버불링 가해행동에 유의한 정적 영향을 미치는 것으로 나타났다. 이는 높은 냉담-무정서 특질을 지닌 중학생일수록 사이버 공간에서 가해 할 가능성 
이 높음을 의미하며, 이는 선행연구(Fanti et al., 2012; Kokkinos $\&$ Voulgaridou, 2017)와 일치하는 바이다. 이와 같은 결과는 냉 담-무정서 특질, 특히 높은 냉담-무정서 특질을 지닌 중학생의 경우 다른 사람이 두려운 감정을 느끼는 상황에서 둔감한 반 응을 보이는데, 이는 정서 처리를 담당하는 편도체의 반응으 로 설명되어질 수 있다. 아동을 대상으로 한 Viding 등(2012)의 연구에 따르면, 낮은 냉담-무정서 특질과 높은 냉담-무정서 특 질을 보이는 각각의 아동에게 두려운 감정을 나타내는 얼굴 사진을 보여주었을 때, 높은 냉담-무정서 특질을 보이는 아동 은 낮은 냉담-무정서 특질을 보이는 아동보다 편도체에서 덜 반응하는 것으로 나타났다. 즉 타인의 감정에 둔감한 반응으 로 인하여 높은 냉담-무정서 특질을 보이는 중학생은 사이버 공간에서 타인에게 공격을 가할 수 있다.

셋째, 중학생의 $\mathrm{ADHD}$ 하위증상과 사이버불링 가해행동 의 관계에서 냉담-무정서 특질의 조절효과를 분석한 결과, 주 의력 결핍과 냉담-무정서 특질은 두 변인이 상호작용하여 사이 버불링 가해행동에 유의한 영향이 미치는 것을 확인할 수 있었 다. 즉 주의력 결핍이 심한 중학생이 높은 냉담-무정서 특질을 보일 경우 사이버불링 가해행동을 할 가능성이 높음을 의미한 다. 주의력 결핍을 보이는 중학생은 부주의한 특성으로 상황에 따른 타인의 감정 상태를 빠르게 인식하는 데 어려움을 보이지 만, 높은 냉담-무정서 특질을 함께 보이면 타인의 감정 상태에 관심이 없고 타인의 반응에 대한 우려가 없기 때문에(Graziano $\&$ Garcia, 2016) 사이버 공간에서 타인에게 공격적으로 행동할 수 있다. 반면 주의력 결핍을 지닌 중학생이 낮은 냉담-무정서 특질을 동시에 보이는 경우, 주의력 결핍이 사이버불링 가해행 동에 미치는 영향력이 유의하지 않음이 확인되었다. 이와 같은 결과가 나타나게 된 이유를 살펴보면, 주의력 결핍과 낮은 냉 담-무정서 특질을 지닌 중학생은 스트레스 상황에서 높은 냉 담-무정서 특질을 지닌 중학생보다 스트레스 호르몬인 코티솔 이 더 높게 나타나는데, 이러한 높은 코티솔을 보이는 중학생 은 자신의 부정적 행동에 대한 처벌을 두려워하여 스트레스 상 황에서 타인에게 공격을 가할 가능성이 낮다(Stadler et al., 2011; van Goozen \& Fairchild, 2006). 때문에 주의력 결핍을 보이는 중 학생이 낮은 냉담-무정서 특질을 함께 보이는 경우 사이버불링 가해행동에 대한 영향력이 낮아질 수 있다. 한편 과잉행동 - 충 동성과 사이버불링 관계에서는 냉담-무정서 특질이 유의한 조 절효과가 나타나지 않았다. 이러한 결과가 나타난 원인을 살펴 보면, 과잉행동 - 충동성과 냉담-무정서 특질을 모두 보이는 중 학생의 경우 높은 충동성을 나타내는데, 이러한 높은 충동성을 보이는 중학생은 언어적 공격성보다 신체적 공격성을 더 많이
나타내며, 화가 나는 상황에서 더욱 충동적으로 신체적 공격을 가할 수 있다(Vigil-Colet, Morales-Vives, \& Tous, 2008). 즉 과잉 행동 - 충동성과 냉담-무정서 특질을 모두 보이는 중학생은 사 이버 공간에서 부정적인 감정을 느낄 때 전자 기기 조작을 통 해 언어적으로 위협을 가하기보다 오프라인 공간에서 더 즉각 적으로 공격적인 행동을 보일 수 있다.

한편, $\mathrm{ADHD}$ 하위증상인 주의력 결핍과 과잉행동 - 충동 성 각각과 사이버불링 가해행동의 관계에서 냉담-무정서 특질 의 조절효과를 분석하였을 때, 그 결과가 모두 유의하게 나왔 다. 즉 주의력 결핍 $(F=20.84, p<.001)$ 과 과잉행동 · 충동성 $(F=$ $29.32, p<.001)$ 각각과 냉담-무정서 특질은 두 변인이 상호작 용하여 사이버불링 가해행동에 유의한 영향을 나타냈다. 그러 나 $\mathrm{ADHD}$ 하위증상은 뚜렷하게 다른 양상을 보이기 때문에 각 하위증상이 상이한 영향을 미칠 수 있다. 따라서 본 연구에서는 $\mathrm{ADHD}$ 하위증상의 독립적인 영향력을 확인하고자 하였다.

본 연구는 $\mathrm{ADHD}$ 하위증상 중 주의력 결핍을 보이는 중학 생이 사이버불링 가해행동을 보일 경우 냉담-무정서 특질을 완화시키는 개입이 효과적일 수 있음을 시사한다. 가장 효율 적인 개입을 위해 중학생의 $\mathrm{ADHD}$ 증상을 파악한 후 $\mathrm{ADHD}$ 증상을 완화시키는 개입과 더불어 냉담-무정서 특질도 함께 낮출 수 있도록 개입한다면 사이버불링 가해행동을 낮추는 데 더욱 효과적일 것이다. 중학생을 대상으로 사이버불링 가 해행동과 관련한 예방 및 치료 프로그램을 진행함에 있어서, $\mathrm{ADHD}$ 증상, 특히 주의력 결핍에 중점을 두고 개입하는 것은 사이버불링 가해행동을 낮추기에 다소 제한적일 수 있다. 따 라서 상담 및 임상현장에서 중학생을 대상으로 사이버불링 가 해행동에 대한 개입과정에서 $\mathrm{ADHD}$ 증상과 냉담-무정서 특 질을 동시에 고려하여, 이러한 특성을 낮출 수 있는 프로그램 을 적용함으로써 사이버불링 가해행동이 줄어들 수 있도록 도 움을 주는 것이 필요하다.

마지막으로 본 연구의 제한점과 후속 연구를 위한 제언은 다음과 같다.

첫째, 본 연구에서는 일반 중학생을 대상으로 하였기 때문 에 $\mathrm{ADHD}$ 로 진단받은 중학생에게 나타나는 특성과 상이하게 나타날 수 있음으로 연구결과를 임상군까지 일반화하기 어려 울 수 있다. 본 연구의 결과를 $\mathrm{ADHD}$ 로 진단받은 중학생에게 적용하기 위해 후속 연구에서 임상군을 대상으로 하여 본 연 구와 동일한 결과가 나타나는지 검증하는 게 필요하다.

둘째, 본 연구에서는 모든 변인을 자기보고식 방법으로 측 정하였다. 이러한 방법은 응답자가 사회적으로 바람직한 태도 에 응답했을 가능성이 높고, 특히 사이버불링 가해행동에 대 
한 문항은 사회적으로 민감한 주제이기 때문에 실제보다 과장 및 축소된 응답을 했을 가능성이 있다. 따라서 후속 연구에서 는 부모, 교사, 전문가 등의 보고와 자기보고 방법을 동시에 고 려하는 것이 필요하다.

셋째, 본 연구에서는 사이버불링 가해행동에 대한 중학생 의 $\mathrm{ADHD}$ 증상과 냉담-무정서 특질이 상호작용하여 영향을 미치는지 검증하였다. 하지만 C. Lee와 Shin (2017)의 연구에 따르면 사이버불링 가해행동만 경험한 청소년은 $6.3 \%$, 피해 만 경험한 청소년은 $14.6 \%$, 가해와 피해를 모두 경험한 청소 년 $13.2 \%$ 로 나타났다. 또한 사이버불링 가해행동과 피해경험 의 상관관계가 높은 것으로 보고되어 사이버불링의 가해와 피해 사이의 악순환이 이루어지고 있음을 알 수 있다(Leung, Wong, \& Farver, 2018). 따라서 후속 연구를 통해 중학생의 $\mathrm{ADHD}$ 증상과 냉담-무정서 특질이 사이버불링 피해경험에도 영향을 미치는지 검증하는 것이 필요하다.

\section{Notes}

This article is a part of the first author's master's thesis submitted in 2018. We present a reanalysis of the original data in this article. This article was presented at the 2018 Annual Spring Conference of the Korean Association of Child Studies.

\section{Conflict of Interest}

No potential conflict of interest relevant to this article was reported.

\section{Ethics Statement}

All procedures of this research were reviewed by IRB (SMWU1711-HR-124).

\section{References}

\section{In English}

American Psychiatric Association. (2013). Diagnostic and statistical manual of mental disorders (5th ed.). Washington, DC: APA Publishing.
Barry, C. T., Frick, P. J., DeShazo, T. M., McCoy, M., Ellis, M., \& Loney, B. R. (2000). The importance of callous-unemotional traits for extending the concept of psychopathy to children. Journal of Abnormal Psychology, 109(2), 335-340. doi:10.1037/0021-843X.109.2.335

Blair, R. J. R. (1995). A cognitive developmental approach to morality: Investigating the psychopath. Cognition, 57(1), 1-29. doi:10.1016/0010-0277(95)00676-P

Braaten, E. B., \& Rosén, L. A. (2000). Self-regulation of affect in attention deficit-hyperactivity disorder (ADHD) and nonADHD boys: Differences in empathic responding. Journal of Consulting and Clinical Psychology, 68(2), 313-321. doi:10.1037/0022-006X.68.2.313

Ceranoglu, T. A. (2018). Inattention to problematic media use habits: Interaction between digital media use and attention-deficit/hyperactivity disorder. Child and Adolescent Psychiatric Clinics of North America, 27(2), 183191. doi:10.1016/j.chc.2017.11.009

Chou, W.-J., Liu, T.-L., Yang, P., Yen, C.-F., \& Hu, H.-F. (2018). Bullying victimization and perpetration and their correlates in adolescents clinically diagnosed with ADHD. Journal of Attention Disorders, 22(1), 25-34. doi:10.1177/1087054714558874

Da Fonseca, D., Seguier, V., Santos, A., Poinso, F., \& Deruelle, C. (2009). Emotion understanding in children with ADHD. Child Psychiatry and Human Development, 40(1), 111-121. doi:10.1007/s10578-008-0114-9

Factor, P. I., Rosen, P. J., \& Reyes, R. A. (2016). The relation of poor emotional awareness and externalizing behavior among children with ADHD. Journal of Attention Disorders, 20(2), 168-177. doi:10.1177/1087054713494005

Fanti, K. A., Colins, O. F., Andershed, H., \& Sikki, M. (2017). Stability and change in callous-unemotional traits: Longitudinal associations with potential individual and contextual risk and protective factors. American Journal of Orthopsychiatry, 87(1), 62-75. doi:10.1037/ort0000143

Fanti, K. A., Demetriou, A. G., \& Hawa, V. V. (2012). A longitudinal study of cyberbullying: Examining riskand protective factors. European Journal of Developmental Psychology, 9(2), 168-181. doi:10.1080/17405629.2011.64 3169

Fontaine, N. M. G., McCrory, E. J. P., Boivin, M., Moffitt, T. E., \& Viding, E. (2011). Predictors and outcomes of joint trajectories of callous-unemotional traits and conduct problems in childhood. Journal of Abnormal Psychology, 120(3), 730-742. doi:10.1037/a0022620

Graziano, P. A., \& Garcia, A. (2016). Attention-deficit hyperactivity disorder and children's emotion dysregulation: A meta-analysis. Clinical Psychology Review, 46, 106-123. doi:10.1016/j.cpr.2016.04.011 
Heiman, T., Olenik-Shemesh, D., \& Eden, S. (2015). Cyberbullying involvement among students with ADHD: Relation to loneliness, self-efficacy and social support. European Journal of Special Needs Education, 30(1), 15-29. doi:10.1080/08856257.2014.943562

Ho, S. S., Chen, L., \& Ng, A. P. Y. (2017). Comparing cyberbullying perpetration on social media between primary and secondary school students. Computers \& Education, 109, 74-84. doi:10.1016/j.compedu.2017.02.004

Kokkinos, C. M., \& Voulgaridou, I. (2017). Relational and cyber aggression among adolescents: Personality and emotion regulation as moderators. Computers in Human Behavior, 68, 528-537. doi:10.1016/j.chb.2016.11.046

Lee, C., \& Shin, N. (2017). Prevalence of cyberbullying and predictors of cyberbullying perpetration among Korean adolescents. Computers in Human Behavior, 68, 352-358. doi:10.1016/j.chb.2016.11.047

Leung, A. N. M., Wong, N., \& Farver, J. M. (2018). Cyberbullying in Hong Kong Chinese students: Life satisfaction, and the moderating role of friendship qualities on cyberbullying victimization and perpetration. Personality and Individual Differences, 133, 7-12. doi:10.1016/j.paid.2017.07.016

Mehari, K. R., Farrell, A. D., \& Le, A. T. H. (2014). Cyberbullying among adolescents: Measures in search of a construct. Psychology of Violence, 4(4), 399-415. doi:10.1037/ a0037521

Mikami, A. Y. (2010). The importance of friendship for youth with attention-deficit/hyperactivity disorder. Clinical Child and Family Psychology Review, 13(2), 181-198. doi:10.1007/ s10567-010-0067-y

Mikami, A. Y., Huang-Pollock, C. L., Pfiffner, L. J., McBurnett, K., \& Hangai, D. (2007). Social skills differences among attention-deficit/hyperactivity disorder types in a chat room assessment task. Journal of Abnormal Child Psychology, 35(4), 509-521. doi:10.1007/s10802-007-9108-5

Milich, R., Balentine, A. C., \& Lynam, D. R. (2001). ADHD combined type and ADHD predominantly inattentive type are distinct and unrelated disorders. Clinical Psychology: Science and Practice, 8(4), 463-488. doi:10.1093/ clipsy.8.4.463

Mitchell, L., \& Hussain, Z. (2018). Predictors of problematic smartphone use: An examination of the integrative pathways model and the role of age, gender, impulsiveness, excessive reassurance seeking, extraversion, and depression. Behavioral Sciences, 8(8), 1-13. doi:10.3390/bs8080074

Pabian, S., \& Vandebosch, H. (2016). (Cyber) bullying perpetration as an impulsive, angry reaction following (Cyber) bullying victimisation? In M. Walrave, K. Ponnet, E. Vanderhoven, J. Haers, \& B. Segaert (Eds.), Youth 2.0: Social media and adolescence (pp. 193-209). Cham, CH:
Springer. doi:10.1007/978-3-319-27893-3_11

Patchin, J. W., \& Hinduja, S. (2015). Measuring cyberbullying: Implications for research. Aggression and Violent Behavior, 23, 69-74. doi:10.1016/j.avb.2015.05.013

Smith, P. K., Mahdavi, J., Carvalho, M., Fisher, S., Russell, S., \& Tippett, N. (2008). Cyberbullying: Its nature and impact in secondary school pupils. Journal of Child Psychology and Psychiatry, 49(4), 376-385. doi:10.1111/j.14697610.2007.01846.x

Sourander, A., Klomek, A. B., Ikonen, M., Lindroos, J., Luntamo, T., Koskelainen, M., . . . Helenius, H. (2010). Psychosocial risk factors associated with cyberbullying among adolescents: A population-based study. Archives of General Psychiatry, 67(7), 720-728. doi:10.1001/ archgenpsychiatry.2010.79

Stadler, C., Kroeger, A., Weyers, P., Grasmann, D., Horschinek, M., Freitag, C., \& Clement, H.-W. (2011). Cortisol reactivity in boys with attention-deficit/hyperactivity disorder and disruptive behavior problems: The impact of callous unemotional traits. Psychiatry Research, 187(1-2), 204-209. doi:10.1016/j.psychres.2010.05.004

Sticca, F., \& Perren, S. (2013). Is Cyberbullying worse than traditional bullying? Examining the differential roles of medium, publicity, and anonymity for the perceived severity of bullying. Journal of Youth and Adolescence, 42(5), 739-750. dol:10.1007/s10964-012-9867-3

Unnever, J. D., \& Cornell, D. G. (2003). Bullying, self-control, and ADHD. Journal of Interpersonal Violence, 18(2), 129147. doi:10.1177/0886260502238731

van Goozen, S. H. M., \& Fairchild, G. (2006). Neuroendocrine and neurotransmitter correlates in children with antisocial behavior. Hormones and Behavior, 50(4), 647-654. doi:10.1016/j.yhbeh.2006.06.021

Viding, E., Sebastian, C. L., Dadds, M. R., Lockwood, P. L., Cecil, C. A. M., De Brito, S. A., \& McCrory, E. J. (2012). Amygdala response to preattentive masked fear in children with conduct problems: The role of callous-unemotional traits. The American Journal of Psychiatry, 169(10), 11091116. doi:10.1176/appi.ajp.2012.12020191

Vigil-Colet, A., Morales-Vives, F., \& Tous, J. (2008). The relationships between functional and dysfunctional impulsivity and aggression across different samples. The Spanish Journal of Psychology, 11(2), 480-487. doi:10.1017/ S1138741600004480

Waschbusch, D. A., Carrey, N. J., Willoughby, M. T., King, S., \& Andrade, B. F. (2007). Effects of methylphenidate and behavior modification on the social and academic behavior of children with disruptive behavior disorders: The moderating role of callous/unemotional traits. Journal of Clinical Child and Adolescent Psychology, 36(4), 629-644. 
doi: $10.1080 / 15374410701662766$

Wehmeier, P. M., Schacht, A., \& Barkley, R. A. (2010). Social and emotional impairment in children and adolescents with ADHD and the impact on quality of life. Journal of Adolescent Health, 46(3), 209-217. doi:10.1016/ j.jadohealth.2009.09.009

Yen, C.-F., Chou, W.-J., Liu, T.-L., Ko, C.-H., Yang, P., \& Hu, H.-F. (2014). Cyberbullying among male adolescents with attention-deficit/hyperactivity disorder: Prevalence, correlates, and association with poor mental health status. Research in Developmental Disabilities, 35(12), 3543-3553. doi:10.1016/j.ridd.2014.08.035

\section{In Korean}

Ahn, S., \& Lee, K. (2014). The effect of parental attachment and peer conformity on adolescents' SNS peer-bullying: Focusing on the moderating effect of disturbance of adaptive functions caused by SNS. The Korea Journal of the Human Development, 21(3), 51-67.

Chung, Y.-J., \& Du, K.-H. (2015). Effects of cyberbully`s empathy ability on aggression level writing replies on internet boards. Korean Journal of Counseling, 16(1), 31-50.

Kim, E. K. (2012). A study on the predictors of youth's cyber bullying (Doctoral dissertation). Retrieved from http://www.riss.kr/ link?id=T12912325

Kim, S., Bang, E., \& Han, Y. (2017). Meta-analysis for exploring predictors of cyberbullying perpetration among youth in South Korea. The Journal of the Korea Contents Association, 17(5), 18-33. doi:10.5392/JKCA.2017.17.05.018

Kim, Y., \& Kang, Y. J. (2016). Comparison between general teenagers and juvenile delinquents in cause and coping methods of stress. Journal of Youth Welfare, 18(1), 261-284. doi:10.19034/KAYW.2016.18.1.11

Korea Internet \& Security Agency. (2017). 2016 survey on the internet usage summary report. Retrieved from KI\&SA website: http://isis.kisa.or.kr

Kwon, E., Son, A.-R., \& Hwang, S.-T. (2010). Validation study for inventory of korea callous-unemotional traits with korean adolescents. The Korea Journal of Youth Counseling, 18(2), $1-16$.

Lee, C. (2016). The causes, effects, and policy measures of cyberbullying among youths: Focusing on interview with youths with cyberbullying experiences. Journal of Political Communication, 43, 231-260.

Lee, J. H. (2017). Predictive variables for cyberbullying perpetration among middle school students: Focusing on individual and parental factors (Master's thesis). Retrieved from http:// www.riss.kr/link?id=T14451069

Lee, S. (2017). Factors that influence middle school student's experience of cyber bullying : A student's awareness of parent's parenting method, and the amount of support from friends (Master's thesis). Retrieved from http://www.riss.kr/ link?id=T14556037

Ministry of Education. (2018). 2018nyeon 1cha hakgyopongnyeok siltaejosa gyeolgwa [2018년 1차 학교폭력 실태조사 결과]. Retrieved from Ministry of Education website: http://www. moe.go.kr

National Information Society Agency. (2016). 「2015nyeon saibeopongnyeok siltaejosa」gyeolgwa bogoseo [「2015년 사이버폭력 실태조사」결과 보고서]. Retrieved from NIA website: https://www.nia.or.kr/

Paek, M. S. (2015). Impact of maternal psychological control on cyberbullying among early adolescents: The mediating effects of relational aggression (Master's thesis). Retrieved from http:// www.riss.kr/link?id=T13770246

Park, J. (2016). The effect of SNS users' motivations and satisfaction on youths' peer relationships (Master's thesis). Retrieved from http://www.riss.kr/link?id=T14177848

Shin, D.-W., \& Lee, S.-M. (2009). Characteristics of the bullying in children with attention-deficit/hyperactivity disorder. Journal of the Korean Academy of Child and Adolescent Psychiatry, 20(2), 90-96.

We, J.-H., \& Chae, K.-M. (2004). Internet addiction disorder of attention-deficit hyperactivity disorder adolescents, psychological characteristics. The Korean Journal of Clinical Psychology, 23(2), 397-416.

Yoo, S.-M., \& Kim, M.-R. (2011). The suggestion and validation on the structural model of the causes of cyber-violence. The Journal of Korean Association of Computer Education, 14(1), 23-33.

\section{ORCID}

Na Young Sim http://orcid.org/0000-0002-2209-156X

So Yean Lee http://orcid.org/0000-0002-1186-2576

Received October 31, 2018

Revision received December 21, 2018

Accepted January 8, 2019 